\title{
Impact of pH Water and Mineralogical Microstructure of Soil Mixed with Wood Waste on the Compressive Strength of Composite Bricks; and Bricks Resistance Modeling
}

\author{
Gilbert Ganga ${ }^{1,2,3^{*}}$, Narcisse Malanda ${ }^{1}$, Diogène Pongui Ngoma ${ }^{1}$, Timothée Nsongo ${ }^{4,5}$, \\ Michel Dzondo Gadet ${ }^{1,2}$
}

\author{
${ }^{1}$ National Advanced School of Engineering, University Marien NGouabi, Brazzaville, Congo \\ ${ }^{2}$ Center for Research and Initiation of Technology Projects (CRIPT), Brazzaville, Congo \\ ${ }^{3}$ Laboratory of Mechanics, Energtics and Engineering, ENSP-UMNG, Brazzaville, Congo \\ ${ }^{4}$ Faculty of Science and Technology, University Marien NGouabi, Brazzaville, Congo \\ ${ }^{5}$ Centerof Géological and Mining Research (CRGM), Brazzaville, Congo \\ Email: *gangegilbert@gmail.com
}

How to cite this paper: Ganga, G., Malanda, N., Ngoma, D.P., Nsongo, T. and Gadet, M.D. (2020) Impact of pH Water and Mineralogical Microstructure of Soil Mixed with Wood Waste on the Compressive Strength of Composite Bricks; and Bricks Resistance Modeling. Open Journal of Civil Engineering, 10, 9-21.

https://doi.org/10.4236/ojce.2020.101002

Received: October 10, 2019

Accepted: January 17, 2020

Published: January 20, 2020

Copyright $\odot 2020$ by author(s) and Scientific Research Publishing Inc. This work is licensed under the Creative Commons Attribution International License (CC BY 4.0).

http://creativecommons.org/licenses/by/4.0/ (c) (i) Open Access

\begin{abstract}
This study includes the manufacture of cement stabilized clay bricks with embedded mahogany chips. The impact of this waste and its interaction with water in the bricks was evaluated on the mechanical properties. The compressive strength tests using a universal press were carried out on bricks with and without adding wood chips. The results obtained show that the incorporation of wood chips into the bricks decreases the compressive strength. This reduction in compressive strength led us to conduct an analysis of clay and water as intrinsic factors, before and after incorporation of untreated wood waste. Thus, a mineralogical analysis of the clay with and without mahogany chips was made using an X-ray diffractometer, using an anticathode of cobalt with the line $\mathrm{K} \alpha$, of wavelength $\lambda=1789 \AA$. After quantification of the mineral constituents, it is noted that the concentration of $\mathrm{SiO}_{2}$ decreases considerably in the clay with addition of wood chips, resulting in the reduction of the compressive strength in these composite materials (from $\mathrm{Rc}=9.26 \mathrm{MPa}$ at $0 \%$ of chips to $3.55 \mathrm{MPa}$ at $8 \%$ ). A mathematical model following the interpolations of Lagrange was then proposed. The analysis of the water resulting from the impregnation of dry wood chips in the water, shows that the water becomes strongly acid ( $\mathrm{pH}=4.3$ at the 7th day of immersion), thus contributing to the reduction of resistance. This analysis of intrinsic factors will allow future studies to take into account the treatment of wood waste by different processes in order to increase the mechanical, thermal and acoustic
\end{abstract}


properties of composite bricks with the same contents, thus generating massive support for the use of its composite materials.

\section{Keywords}

Clay Bricks, Mineralogical Analysis, Wood Chips, Compressive Strength, $\mathrm{pH}$ Water

\section{Introduction}

The destruction of the ozone layer by greenhouse gases has led the scientific community to address the issue of reducing the production of its gases. In Central Africa, particularly in Congo, wood waste produced by the intense activity of the wood industry is destined to be burned, thus polluting the atmosphere. One of the many solutions to this problem is the management of this waste by incorporation into civil engineering works. Thus the incorporation of wood waste in building materials has been the subject of several works. Most of these works, as shown by the studies of [1]-[9], focused on the influence of this waste on the mechanical, thermal and acoustic properties of earth concretes. It has been noted in this work that the incorporation of the chips and sawdust in the blocks of cement-stabilized ground, involves a considerable reduction in the mechanical properties of these composite materials compared to the blocks of stabilized ground ( $0 \%$ of wood) [10]. This decrease has been interpreted in terms of physico-chemical exchanges between wood waste and clay.

However, there is practically no work on the intrinsic and extrinsic factors that lead to the lowering of the mechanical properties of these composite bricks [2].

In this work, we are interested in the investigation of the influence of the mineralogical structure of stabilized earth, before and after the incorporation of mahogany wood chips, and the chemical characteristics of water as intrinsic factors, on the compressive strength of bricks. The material soil coming predominantly from the physical and chemical deterioration of the rock-mother has to a certain extent, the stability of the rocks of origin. Our motivation for this study relies on the fact that we did not find any reference on the former research works, concerning the influence of intrinsic factors on the mechanical properties of bricks.

\section{Materials and Methods Used}

\subsection{Mineralogical Analyzes by X-Rays Diffraction (XRD) of the Clay Samples}

In this study, we have used the method of diffraction, according to Bragg, in order to carry out the analysis within the laboratory.

Two methods of investigation by X-rays diffraction have been classically ap- 
plied by the analyses laboratories:

- The analysis over the full powder has provided the crystalline elements of the mixture and a semi-quantification of all current minerals.

- The analysis of the clay fraction (lower than $2 \mu \mathrm{m}$ ) extracted from materials and processed in the shape of directed blades.

We have chosen the mineral analysis over the full powder, with the objective of analyzing the impact of the mineral structure of clay, before and after the incorporation of wood shavings related to the resistance of composite bricks.

The lines diffracted according to the Bragg angle are recorded by a meter of the Geiger Müller type, which is placed in order to receive the diffracted rays by the sample under the angle $2 \theta$.

We have also used a beam of X-rays, the line $\mathrm{K} \alpha$ of the cobalt, wavelength $\lambda=$ $1789 \AA$.

\subsubsection{Material and Experimental Conditions}

The essential material used within the laboratory consists of: a crusher, and a diffractometer Siemens D5000.

Bricks with and without shavings have been crushed to obtain a fine powder, in the shape of millimetre-length fragments called crystallites. After crushing, a sample of powder has been collected and subjected to the analysis by diffractometry of $\mathrm{x}$-rays within a cobalt tube (Figure 1 ).

The experimental conditions for this analysis have been: the threshold of detection is about 5\%; the sweeping of the angular positions $2 \theta$ varies from $4^{\circ}$ to $84^{\circ}$; the scanning rate is $0.02^{\circ}$ a second; the time of counting of the detector is 5 seconds per step; the sample turns from $4^{\circ}$ to $84^{\circ} 2 \theta$, x-rays are generated by a cobalt tube $(\lambda \mathrm{K} \alpha 1=1789 \AA)$.

\subsubsection{Identification Method of the Crystalline Phases}

Generally the identification of a crystallized phase is made by the confrontation of the experimental diffractogram with a database of known compounds.

\section{* Creation of a necessary database}

Three types of software that we had at our disposal, XRD2Dscan; XRDCALC; and Match 2! have been considered. The spectra of the phase lines have constituted our database, by stressing the mineral clay spectra. We know that angular positions (related to the reticular distances " $\mathrm{d}$ ") and the intensities "I" of the various observed lines in a diffractogram have been specific to a known product: Montmorillonite, Kaolinite, illite, chlorite, quartz, calcite, anatase, etc.

Using the software FotoMix, software of assembly, we have initially fixed angles $2 \theta$ so that the angular scale is the same one.

Then, we have proceeded by the superposition of each "spectrum of lines" of the database phases to identify the spectrum whose lines go more with certain peaks of the experimental diffractogram (Figure 2 and Figure 3 ).

After several superpositions, we have observed a coherent fitment between certain peaks and certain lines of the phases of kaolinite (in blue), of quartz (in 
red), of calcite (in green) and the anatase (in move) whose lines go more with them.

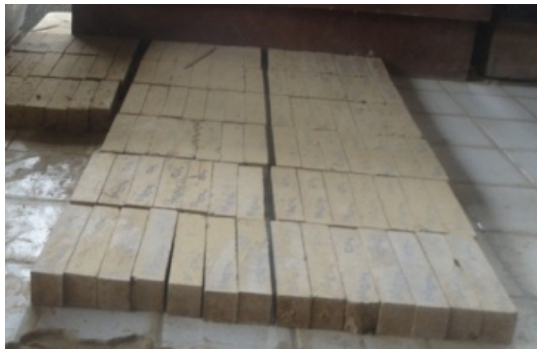

(a) Brick samples

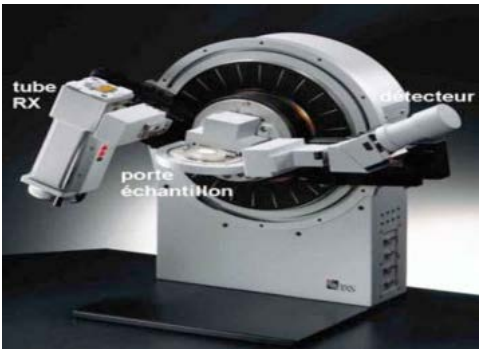

(b) Photo of an X-ray diffractometer

Figure 1. Sample of stabilized clay bricks to be ground and X-ray diffractometer.

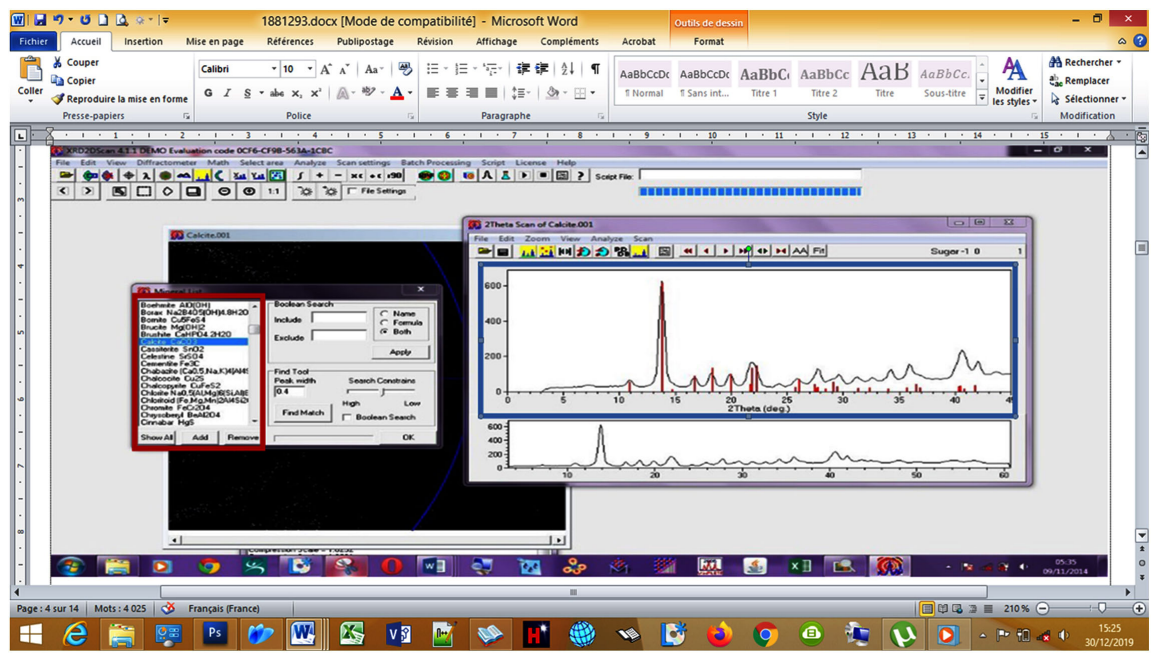

Figure 2. XRD2DScan software in use. Red dial on the left represents the mineral list included in the software; and the blue dial on the right is the referential diffractogram $(\lambda$ $\mathrm{K} \alpha 1=1789 \AA$ ) of Calcite (the lines are in red).

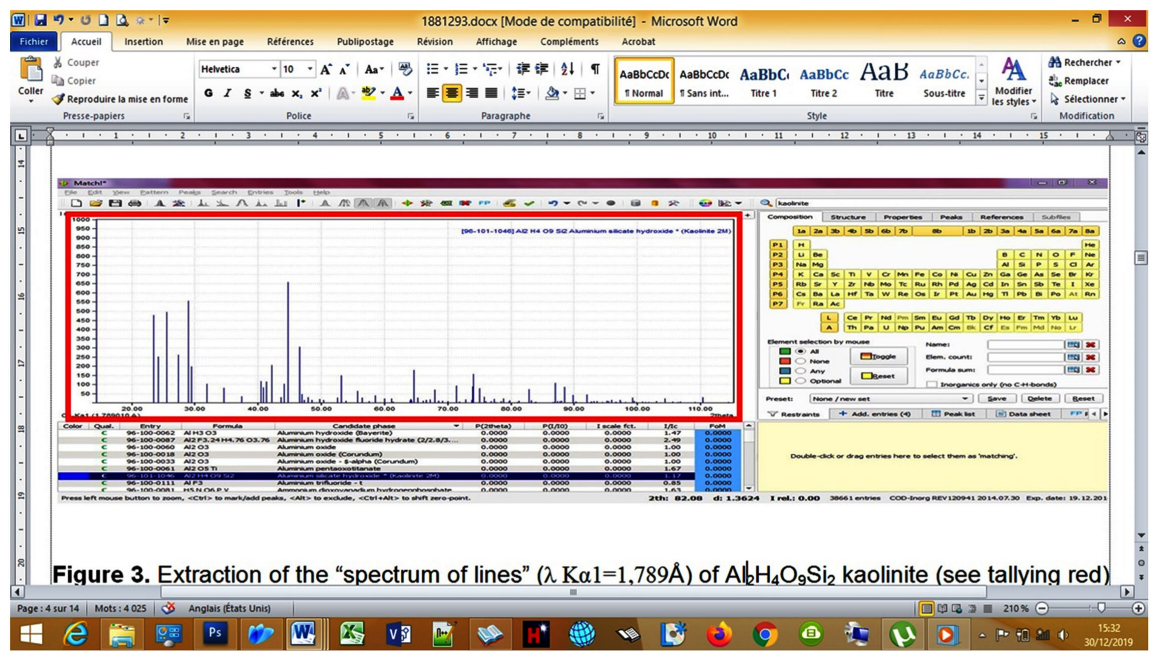

Figure 3. Extraction of the "spectrum of lines" ( $\lambda \mathrm{K} \alpha \mathrm{l}=1789 \AA$ ) of $\mathrm{Al}_{2} \mathrm{H}_{4} \mathrm{O}_{9} \mathrm{Si}_{2}$ kaolinite (see tallying red) in the software Match 2! 


\subsection{Compressive Strength Measurement}

Parallel-piped bricks $(160 \mathrm{~mm} \times 40 \mathrm{~mm} \times 40 \mathrm{~mm})$, are centered between the plates of a universal press of mark IGM, and are responsible for continuous manner at the mean velocity of $0.20 \mathrm{MPa} / \mathrm{s}$ by a compressive force until crushing. We have calculated thereafter the compressive strength, which is the relationship between the maximum compressive force and the cross-section of the crushed test-tube:

$$
R C=\frac{F C}{S o}
$$

with:

- Rc. Compressive strength in (MPa);

- $F$ c. Maximum compressive force reached (N);

- So: Initial surface of the cross-section of the test-tube before crushing $\left(\mathrm{mm}^{2}\right)$.

\section{Results and Discussion}

\subsection{Resistance Test in Compression of Clay-Stabilized Bricks with Incorporated Mahogany Wood Shavings}

Figure 4 shows the variation in compressive strength as a function of mahogany wood chip content. We observe a decrease in compressive strength of bricks with increasing mahogany wood chip content.

Considering the brick without adding chips $(0 \%)$ as a reference, we find that this decrease is about half less than the compressive strength of the brick with the addition of $2 \%$ chips (9.26 MPa for brick with $0 \%$ chips and $4.95 \mathrm{MPa}$ with $2 \%$ mahogany chips); then, it is slower as the chip content increases.

These results are in agreement with those found by:

- Khelifi and Belouettar which showed in their work, that the mechanical resistances of the composite concretes decrease with the increase in the wood fiber rate in the concrete [4].

- Ganga who has also showed in research works for his doctoral thesis that the compactness of composite bricks decreases with the increase in the rate of the wood chips; factor which involves the fall of compressive strength [2].



Figure 4. Variations in Compressive Strength of clay bricks stabilized at $4 \%$ of cementas a function of Content Chips. 
However, it is certain that the reduction in the rate of compactness generated by the incorporation of the shavings of wood in bricks would not be the single cause of the fall of resistance.

Indeed, Tamba et al. have shown in their works that the compressive strength of these composite bricks can be improved by using the treated shavings [7].

Ganga et al. have also shown in their study on the analysis of the extrinsic factors, that the compressive strength of these composite bricks can be improved by using the high-temperature drying [11].

Thus, we have directed ourselves towards the analysis of the other intrinsic factors.

\subsection{Modeling the Compressive Strength of Composite Bricks}

From experimental laboratory results, we sought to find a mathematical model that would approach the experimental compressive strength of bricks.

\subsubsection{Mathematical Formulation of the Problem}

\section{Position of the problem}

Let $R_{n}[x]$ be the vector space formed by all polynomials of degree less than or equal to $n$. It is well known that $R_{n}[x]$ has dimension $n+1$ and that its canonical basis is given by $\left\{1, x, x^{2}, \cdots, x^{n}\right\}$.

Suppose we want to find a polynomial $P_{n}$ of degree $n>0$ which, for values $x_{0}, x_{1}, x_{2}, \cdots, x_{n}$ distinct data (called interpolation nodes), take the values $y_{0}, y_{1}, y_{2}, \cdots, y_{n}$ respectively; i.e.:

$$
P_{n}\left(x_{i}\right)=y_{i} \text { for } 0 \leq i \leq n
$$

If such a polynomial exists, it is called an interpolating polynomial or an interpolating polynomial.

\subsubsection{Method of Lagrange}

When we write the polynomial $P_{n}$ in the canonical basis of $R_{n}[x]$, the problem is to determine the $(n+1)$ coefficients $a_{0}, a_{1}, \cdots, a_{n}$; such as

$$
P_{n}(x)=a_{0}+a_{1} x+a_{2} x^{2}+\cdots+a_{n} x^{n}
$$

We wonder whether there exists another base $\left\{L_{0}, L_{1}, \cdots, L_{n}\right\}$ of $R_{n}[x]$ such that the polynomial $P_{n}$ is written:

$$
P_{n}(x)=y_{0} L_{0}(x)+y_{1} L_{1}(x)+\cdots+y_{n} L_{n}(x)
$$

in other words, if there exists a base such that the coordinates of the polynomial in this base are anything else only the known values $y_{0}, y_{1}, \cdots, y_{n}$.

To find such a base, let us start by imposing the passage of the polynomial by $(n+1)$ given points: the $(n+1)$ relations impose the condition:

$$
L_{i}(x)=\left\{\begin{array}{cc}
1 & \text { if } i=j \text { for } 0 \leq i, j \leq n \\
0 & \text { else }
\end{array}\right.
$$

which give 


$$
L_{i}(x)=\prod_{j=0, i \neq j}^{n} \frac{x-x_{j}}{x_{i}-x_{j}}
$$

Clearly, the numerator of $L_{i}(x)$ is a product of $\mathrm{n}$ terms $\left(x-x_{j}\right)$ with $i \neq j$ and is therefore a polynomial of degree $n$.

\subsubsection{Theorem: Interpolation of Lagrange}

Given $(n+1)$ distinct points, $x_{0}, x_{1}, \cdots, x_{n}$ and $n+1$ corresponding values, $y_{0}, y_{1}, \cdots, y_{n}$, there exists a single polynomial $P_{n} \in R_{n}[x]$ such that $P_{n}\left(x_{i}\right)=y_{i}$ for $i=0, \cdots, n$ that we can write in the form:

$$
P_{n}(x)=\sum_{i=0}^{n} y_{i} L_{i}(x) \in R_{n}[x] \text { where } L_{i}(x)=\prod_{j=0, i \neq j}^{n} \frac{x-x_{j}}{x_{i}-x_{j}}
$$

This relation is called the Lagrange interpolation formula and the $L_{i}(x)$ polynomials are the characteristic Lagrange polynomials.

So, for $n=4$ we have

$$
P_{4}(x)=\sum_{i=0}^{4} y_{i} L_{i}(x)=y_{0} L_{0}(x)+y_{1} L_{1}(x)+y_{2} L_{2}(x)+y_{3} L_{3}(x)+y_{4} L_{4}(x)
$$

with

$$
\left\{\begin{array}{l}
L_{0}(x)=\frac{x^{4}-20 x^{3}+140 x^{2}-400 x+384}{384} \\
L_{1}(x)=\frac{-x^{4}+18 x^{3}-104 x^{2}+192 x}{96} \\
L_{2}(x)=\frac{x^{4}-16 x^{3}+76 x^{2}-96 x}{64} \\
L_{3}(x)=\frac{-x^{4}+14 x^{3}-56 x^{2}+64 x}{96} \\
L_{4}(x)=\frac{x^{4}-12 x^{3}+44 x^{2}-48 x}{384}
\end{array}\right.
$$

Thus the mathematical model that approaches the experimental results of the compressive strength of composite bricks is described by the interpolation polynomial $P(x)$, and is represented in Figure 5.

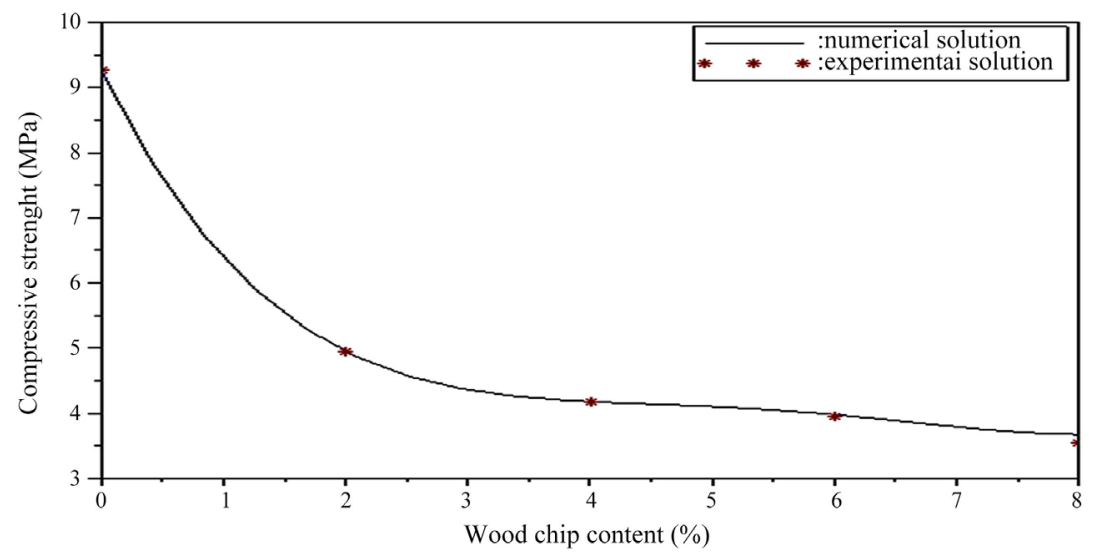

Figure 5. Numerical and experimental variation in compressive strength of clay bricks stabilized at $4 \%$ of cement as a function of Content Chips. 
Thus the mathematical model which approaches the experimental results of resistance in compression of composite bricks is described by the polynomial of interpolation $P(x)$, and is represented by Figure 4 .

$$
P(x)=0.006 x^{4}-0.134 x^{3}+1.079 x^{2}-3.826 x+9.26
$$

\subsection{Study by X-Rays of the Structure of Soil}

In order to determine the structure of clay, we have carried out a mineralogical analysis by X-rays of the clay sample before and after the incorporation of the wood shavings; the anticathode used being made of cobalt, with the line $\mathrm{K} \alpha$ of wavelength $\lambda=1789 \AA$.

\subsubsection{Clay without Shavings}

The analysis results of the clay sample have given the diagram of diffraction presented on Figure 6. We have used the FotoMix software to identify the various peaks which appear. The diffractogram obtained has shown the presence of:

- kaolinite (noted K), formula: $\mathrm{Al}_{2} \mathrm{H}_{4} \mathrm{Si}_{2} \mathrm{O}_{9}$;

- Quartz alpha (noted Q), formula $\mathrm{SiO}_{2}$.

The threshold of detection is about $5 \%$. The $\mathrm{x}$-axis has been represented by the angle of diffraction $2 \theta$ (in ${ }^{\circ}$ ), and the y-axis has been represented to by the intensity of diffraction (in blows " $\mathrm{Cp} \cdot \mathrm{s}^{-1}$ "). The sweeping on this diagram goes from $2^{\circ}$ to $60^{\circ}$ and the intensity varies from 0 to 750 blows a second.

\subsubsection{Clay after Incorporation of the Wood Waste of Mahogany Tree (4\%)}

The results obtained are presented on Figure 7.

The identified phases are: quartz alpha (noted Q) of formula $\mathrm{SiO}_{2}$; kaolinite $1 \mathrm{~A}$ (noted $\mathrm{K}$ ) of formula $\mathrm{Al}_{2}\left(\mathrm{Si}_{2} \mathrm{O}_{5}\right)(\mathrm{OH})_{4}$; calcite traces (noted $\mathrm{C}$ ) of formula $\mathrm{CaCO}_{3}$ and anatase (noted $\mathrm{A}$ ) of formula $\mathrm{TiO}_{2}$.

The marks of calcite and anatase are due to the presence of cement in the mixture of clay, cement and wood shavings.

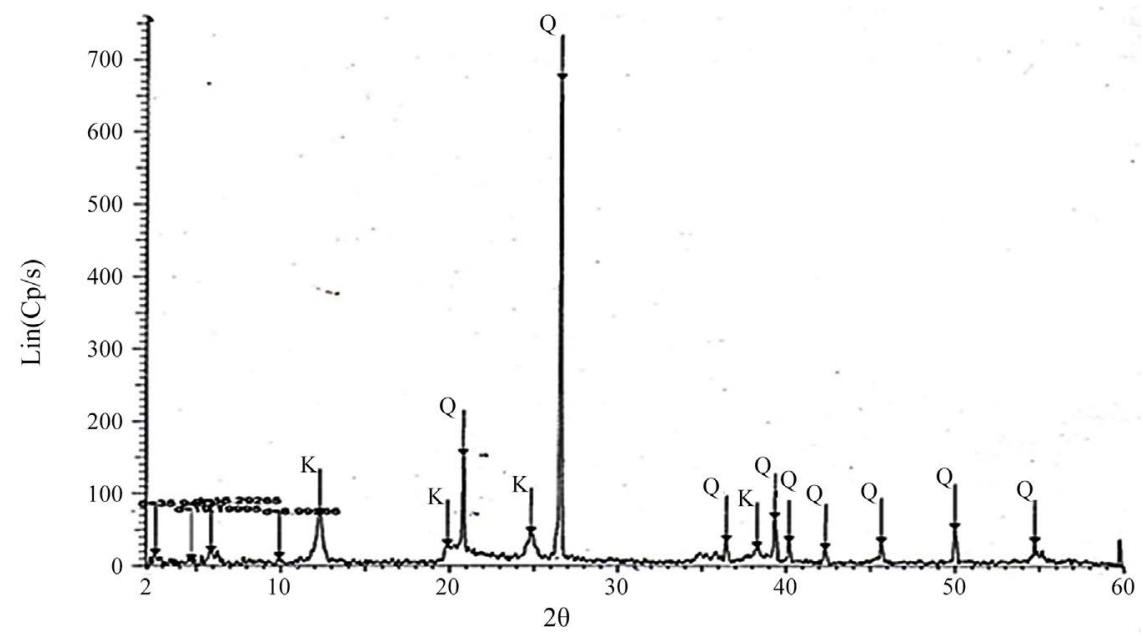

Figure 6. Diffractogram of the rough clay sample with $\lambda(\mathrm{K} \alpha$ line of cobalt $)=1789 \AA$. 

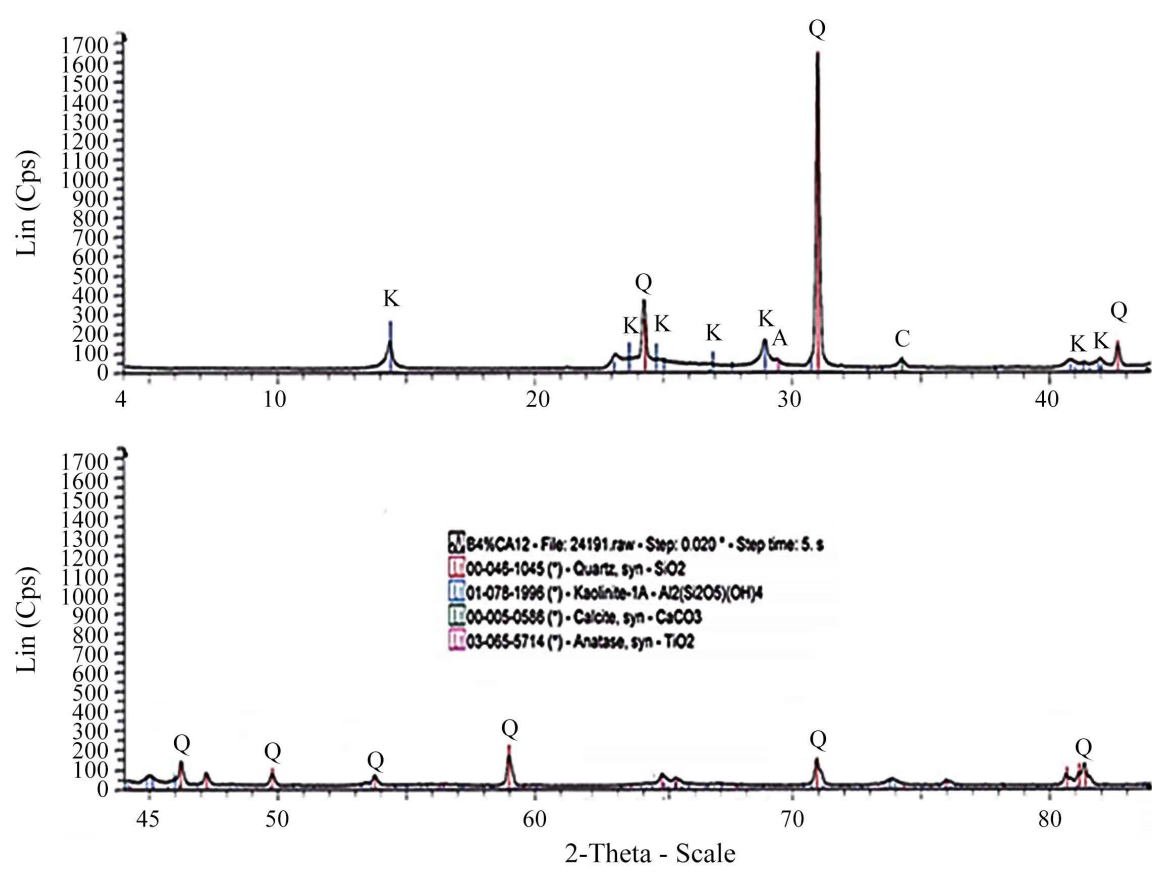

Figure 7. Diffractogram of clay-polycristallined powder mixed with the mahogany tree shavings $(\lambda \mathrm{K} \alpha 1=1789 \AA)$.

\subsubsection{Quantification of the Identified Mineral Phases}

The estimates of the concentration of the mineral components can be obtained by using the method of "Peak-height Ratio" and only give indications on the contents. Through this method, the vertical distance between the apex of each interested peak and the basic line are measured and multiplied by the corrective corresponding factor. The results of each multiplication are then added up for various identified minerals; their respective rates about the material are ascertained afterwards according to a simple rule of three and are shown up as follows (Table 1):

By comparing the concentrations of the mineral components of clay before and after the incorporation of wood waste, we have ascertained that:

1) The concentration of $\mathrm{SiO}_{2}$ (of quartz) in clay without shavings (68.32\%), is higher than that of clay with incorporation of the mahogany tree shavings (58.21\%). Yet, the high content in silica demonstrates the acidity of the rock; i.e. the ratio of the quantity of oxygen determined by silica to the quantity of oxygen set by all the other cations. The acid rocks having a percentage of $\mathrm{SiO}_{2}$ higher than $65 \%$, the clay used for the manufacture of bricks is the result of the deterioration of an acid rock (rate of $\mathrm{SiO}_{2}: 68.32 \%$ ). The chemical reactions between clay and cement with high contents (pozzolanic reactions) form new products which contribute indeed in the final value of the resistance of a cement-stabilized ground [12]. That explains the fact that compressive strength of the clay-stabilized bricks without addition ( $0 \%$ Mahogany tree Shavings, Figure 4 ), is higher than that of bricks with incorporated wood shavings. 
Table 1. Results of the quantification of the mineral phases.

\begin{tabular}{ccc}
\hline & Rough clay & $\begin{array}{c}\text { Clay after incorporation } \\
\text { of the shavings of wood }\end{array}$ \\
Quartz alpha & $68.32 \%$ & $58.21 \%$ \\
Kaolinite & $31.68 \%$ & $24.60 \%$ \\
Some traces of anatase & - & $8.88 \%$ \\
Some traces of calcite & - & $8.31 \%$ \\
\hline
\end{tabular}

2) The concentration of $\mathrm{SiO}_{2}$ in the same argillaceous mineral decreases after incorporation of the wood waste $(58.21 \%)$, placing consequently this mineral among the products of the deterioration of not very acid rock (or intermediaries: $\left.52 \%<\mathrm{SiO}_{2}<65 \%\right)$. This means that the incorporation of untreated wood waste with high contents in the clay-stabilized bricks certainly makes clay amorphous; what begets the fall of the mechanical properties (compressive strength) of these bricks (Figure 3).

But it is certain that the observed decrease of the $\mathrm{SiO}_{2}$ concentration in these composite materials would not be the only intrinsic factor that would have caused the decrease in compressive strength.

\subsection{Analysis of the Treatment Water of Wood Chips}

It was used in this study, untreated mahogany wood chips. However, Tamba et al. (2007) have shown in their work that the compressive strength of these composite bricks can be improved by using wood chips treated with water.

\subsubsection{Influence of $\mathrm{pH}$ Water on the Compressive Strength of Clay Bricks Stabilized at 6\% Cement and with Incorporated Wood Waste}

We have analyzed in the laboratory of the Research Group in Exact and Natural Sciences in abbreviation (GRSEN) of the Directorate General of Scientific and Technological Research, ordinary drilling water, then that in which the mahogany wood chips were immersed for seven (7) days (water resulting from the supposed treatment of wood waste by water); and then measured the physicochemical parameters of the waters whose results are shown in Table 2. These results show that the chemical elements in ordinary water are low compared to the water containing the wood chips and prove that water becomes strongly acid after immersion of mahogany wood [11].

\subsubsection{Evolution of the $\mathrm{pH}$ of the Drilling Water by Interaction with Mahogany Wood Chips}

We have shown in Figure 6 the variation of the $\mathrm{pH}$ of water containing mahogany chips. We find that the $\mathrm{pH}$ decreases with time and becomes almost constant after seven (7) days of immersion of the wood chips in the water (Figure 8). 


\subsubsection{Effect of the Nature of Water on the Compressive Strength of Bricks}

Figure 9 shows the effect of the nature of the water on the compressive strength of clay bricks stabilized with $6 \%$ cement mixed with mahogany wood chips. We note that the compressive strength of bricks made with acidulated water by interaction with dry wood chips incorporated (brick with added chips), is lower than that of bricks with water without chip influence (bricks with $0 \%$ chips), whatever the mahogany chip content. This means that the acidity of water greatly reduces the mechanical characteristics of composite bricks. In other words, the use of untreated wood waste (leading to the acidification of mixing water) in the manufacture of composite bricks leads to a decrease in the compressive strength of these materials; which confirms the result reported in the literature by [4] [6] $[7]$.

Table 2. Results of the water analysis [11].

\begin{tabular}{ccccccccc}
\hline & $\mathrm{pH}$ & $\mathrm{t}^{\circ}$ & $\mathrm{Ca}^{2+}$ & $\mathrm{K}^{+}$ & $\mathrm{Mg}^{2+}$ & $\mathrm{Mn}^{2+}$ & $\mathrm{PO}_{4}^{3-}$ & $\mathrm{Al}^{3+}$ \\
\hline $\begin{array}{c}\text { Drilling water } \\
\text { containing } \\
\text { wood chips }\end{array}$ & 4.3 & 26.2 & $\begin{array}{c}13 \\
\mathrm{mg} \cdot \mathrm{L}^{-1}\end{array}$ & $\begin{array}{c}5.7 \\
\mathrm{mg} \cdot \mathrm{L}^{-1}\end{array}$ & $\begin{array}{c}21 \\
\mathrm{mg} \cdot \mathrm{L}^{-1}\end{array}$ & $\begin{array}{c}0.05 \\
\mathrm{mg} \cdot \mathrm{L}^{-1}\end{array}$ & $\begin{array}{c}1.05 \\
\mathrm{mg} \cdot \mathrm{L}^{-1}\end{array}$ & $\begin{array}{c}0.8 \\
\mathrm{mg} \cdot \mathrm{L}^{-1}\end{array}$ \\
$\begin{array}{c}\text { Ordinary } \\
\text { drilling water }\end{array}$ & 7.08 & 26.8 & $\begin{array}{c}6 \\
\mathrm{mg} \cdot \mathrm{L}^{-1}\end{array}$ & $\begin{array}{c}0.123 \\
\mathrm{mg} \cdot \mathrm{L}^{-1}\end{array}$ & $\begin{array}{c}3.66 \\
\mathrm{mg} \cdot \mathrm{L}^{-1}\end{array}$ & $\begin{array}{c}0.02 \\
\mathrm{mg} \cdot \mathrm{L}^{-1}\end{array}$ & $\begin{array}{c}0.008 \\
\mathrm{mg} \cdot \mathrm{L}^{-1}\end{array}$ & $\begin{array}{c}0.043 \\
\mathrm{mg} \cdot \mathrm{L}^{-1}\end{array}$
\end{tabular}

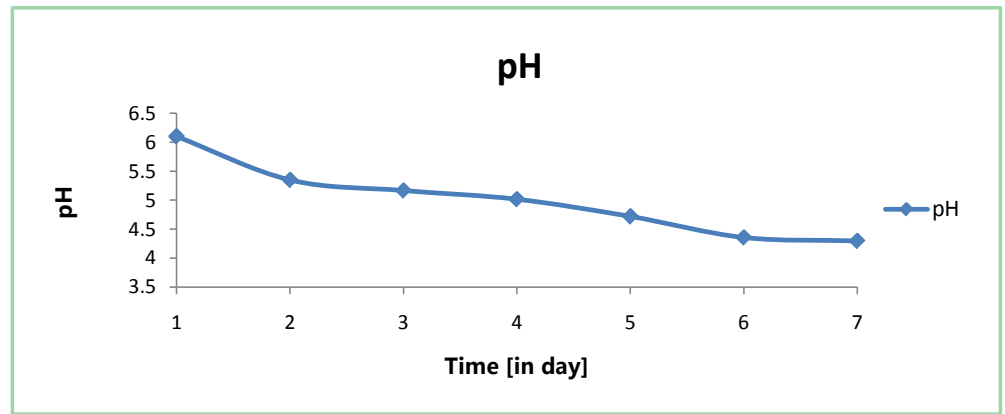

Figure 8. Evolution of the $\mathrm{pH}$ of water containing mahogany wood chips as a function of time.

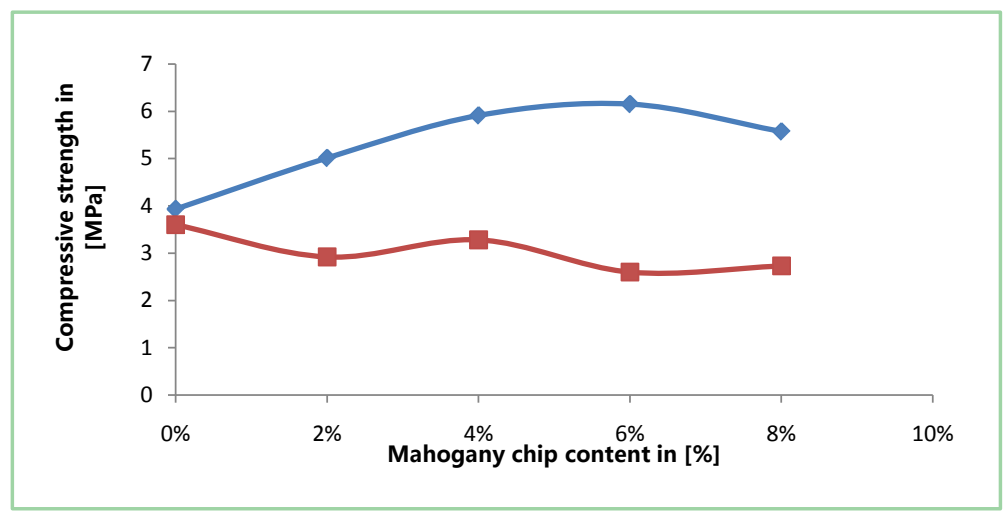

Figure 9. Variation in the compressive strength of clay bricks stabilized at $6 \%$ cement as a function of chip content and water nature [11]. 


\section{Conclusions and Future Work}

In this work, we have studied the influence of wood waste on the mineralogical structure of stabilized clay bricks and on the nature of water; the study revealed the following conclusions.

- Incorporation of high-grade wood waste into stabilized clay bricks reduces the amount of $\mathrm{SiO}_{2}$ in the clay.

- The reduction of the $\mathrm{SiO}_{2}$ content in the stabilized clay bricks leads to a decrease in the compressive strength of the stabilized clay bricks.

- The untreated wood chips incorporated into the stabilized clay bricks make amorphous clay at high levels.

- The $\mathrm{pH}$ of ordinary water decreases by interaction with immersed wood chips.

- The immersion of the mahogany wood chips reveals chemical elements such as $\mathrm{Ca}^{2+}, \mathrm{K}^{+}, \mathrm{Mg}^{2+}, \mathrm{Mn}^{2+}, \mathrm{PO}_{4}^{3-}$ and $\mathrm{Al}^{3+}$ ions and makes the water strongly acidic.

- Incorporation of untreated wood waste into stabilized clay bricks leads to acidification of the mixing water; this results in reducing the compressive strength of the bricks.

The chemical interaction of the wood waste in the mixture: clay + cement + chips + water, likely to alter the microstructure of the clay and to acidify the water will be the subject of a complementary study.

\section{Acknowledgements}

We do thank the Managing Director of the "Office of Building Control and Public Works", and the physics head of Department of National Teacher Training College, who have enabled and allowed us to carry out some experimental tests in their laboratory.

\section{Conflicts of Interest}

The authors declare no conflicts of interest regarding the publication of this paper.

\section{References}

[1] Ganga, G., Nsongo, T., Elenga, H., Moukala, L.M., Nzabana, A. and Elenga, N.F. (2017) Impact of the Wood Chips Content on the Mechanical Properties and Relation between the Young Modulus and the Compressive Strength of Clay Bricks Stabilized. Research Journal of Physical Sciences, 5, 1-5. http://www.isca.in/PHY SCI/Archive/v5/i5/1.ISCA-RJPS-2017-008.pdf

[2] Ganga, G. (2016) Study of the Influence of the Content of the Chips of Wood on the Mineralogical Structure, Mechanical and Acoustic Properties of Laterite and Clay Bricks. Ph.D. Dissertation, University Marien Ngouabi, Congo, Brazzaville.

[3] Ganga, G. (2013) Impact of the Shavings of Wood on the Mechanical Properties and Acoustic of Stabilized Ground Bricks. Memory of Master Degree, National Advanced School of Engineering, YaoundéI University, Cameroon. 
[4] Khelifi, W. and Belouettar, R. (2012) Influence of the Nature of the Shavings on the Physical and Mechanical Characteristics of the Concretes Containing Shavings. $20^{\text {th }}$ University Meeting of Civil Engineering, Chambéry France, 1-7.

[5] Mekhermeche, A. (2012) Contribution à l'étude des propriétés mécaniques et thermiques des briques en terre en vue de leur utilisation dans la restauration des Ksour sahariennes. Mémoire de Magister en Génie Civil, Université de Ouargla. Algérie.

[6] Taoukil, D., El bouardi, A, Ajzoul, T. and Ezbakhe, H. (2011) Mechanical and Hydrous Characterization of a Concrete Reduced with Wood Residues. International Review of Heliotechnic, $\mathrm{n}^{\circ} 43$.

[7] Tamba, S., Voumbo, M.L., Wareme, A., Gaye, S. and Sissoko, G. (2007) Durability of Lightweight Concrete Made of Wood Shavings. Journal Science, 7, 67-72.

[8] Meukam, P. (2004) Characterization of Local Materials for the Thermal Isolation of the Buildings. Ph.D. Dissertation, Yaounde I University, Cameroon.

[9] Gaye, S. (2001) Characterization of the Mechanical Properties, Acoustic and Thermics of Local Materials of Construction in Senegal. Ph.D. Dissertation, Cheikh Anta Diop University, Senegal.

[10] Ganga, G., Nsongo, T., Elenga, H., Mabiala, B., Tamo, T.T. and Nzonzolo (2014) Effect of Incorporation of Shavings and Wood Dust Mahogany on Mechanical and Acoustic Behavior of Brick Clay. Journal of Building Construction and Planning Research, 2, 198-208. https://doi.org/10.4236/jbcpr.2014.23018

[11] Ganga, G., Elenga, H., Nsongo, T. and Tamo, T.T. (2014) Effect of Environmental Temperature and $\mathrm{pH}$ Water on Compressive Strength of Clay Brick Mixed Wood Chips Mahogany Based Building Materials. Industrial Financial \& Business Management (IFBM), 2, 296-299.

[12] Akpokodje, E.G. (1985) The Stabilization of Some Arid Zone Soils with Cement and Lime. Quarterly Journal of Engineering Geology London, 18, 173-180.

https://doi.org/10.1144/GSL.QJEG.1985.018.02.06 